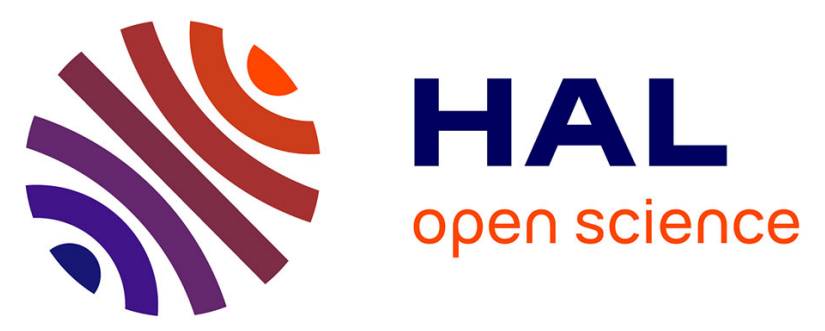

\title{
Interest towards human, animal and object in children with autism spectrum disorders: an ethological approach at home
}

Marine Grandgeorge, Yannig Bourreau, Zarrin Alavi, Eric Lemonnier, Sylvie Tordjman, Michel Deleau, Martine Hausberger

\section{To cite this version:}

Marine Grandgeorge, Yannig Bourreau, Zarrin Alavi, Eric Lemonnier, Sylvie Tordjman, et al.. Interest towards human, animal and object in children with autism spectrum disorders: an ethological approach at home. European Child and Adolescent Psychiatry, 2014, 24 (1), pp.83-93. 10.1007/s00787-0140528-9 . hal-01016382

HAL Id: hal-01016382

https://hal-univ-rennes1.archives-ouvertes.fr/hal-01016382

Submitted on 30 Jun 2014

HAL is a multi-disciplinary open access archive for the deposit and dissemination of scientific research documents, whether they are published or not. The documents may come from teaching and research institutions in France or abroad, or from public or private research centers.
L'archive ouverte pluridisciplinaire HAL, est destinée au dépôt et à la diffusion de documents scientifiques de niveau recherche, publiés ou non, émanant des établissements d'enseignement et de recherche français ou étrangers, des laboratoires publics ou privés. 
Interest towards human, animal and object in children with autism spectrum disorders: an ethological approach at home

Marine Grandgeorge ${ }^{\mathrm{a}, \mathrm{b}, \mathrm{c}^{*}}$, Yannig Bourreau ${ }^{\mathrm{c}}$, Zarrin Alavi ${ }^{\mathrm{d}}$, Eric Lemonnier ${ }^{\mathrm{a}}$, Sylvie Tordjman $^{\mathrm{e}}$, Michel Deleau ${ }^{\mathrm{f}}$, Martine Hausberger $^{\mathrm{c}}$

${ }^{\text {a }}$ Laboratory of Neurosciences de Brest, EA 4685, University of Bretagne Occidentale, Brest, France

${ }^{\mathrm{b}}$ Child Psychiatry Service, Centre de Ressources Autisme, CHRU of Brest, Brest, France ${ }^{\mathrm{c}}$ Université de Rennes 1, Ethos, UMR 6552, Ethologie animale et humaine, Rennes, France d INSERM, CIC 0502, CHRU de Brest, France

${ }^{\mathrm{e}}$ Department of Child and Adolescent Psychiatry, CHU Guillaume Régnier, Rennes, France

${ }^{\mathrm{f}}$ Université Rennes 2, CRPCC, EA 1285, Centre de recherches en psychologie, cognition et communication, Rennes, France

Correspondence concerning this article should be addressed to

Marine Grandgeorge

Centre de Ressources Autisme, CHRU de Brest, Hôpital de Bohars, 29820 Bohars, France

Email : marine.grandgeorge@chu-brest.fr 


\begin{abstract}
Autistic spectrum disorders (ASD) are characterized by attention deficits in communication and social interactions, and a lack of interest in people. Data are mostly based on clinical situations. However, recent studies have shown a more mixed situation where children with ASD (ASD children) displaying interest towards humans, in both experimental and natural settings. The aim of this study was to assess the interest of ASD children in a natural standardized home setting. Here, we hypothesized that ASD children would display more interest towards animate stimuli - human and pet - when in the child's home than in the lab experimental setting. We used an ethological approach involving observations, a methodological alternative to lab static techniques, to investigate the behaviour of ninety 6-to12-year old ASD and typical development (TD) children. Our results were consistent with those of the literature revealing that the ASD children displayed interest towards animate stimuli as did children with typical development (TD children). Interestingly, while the ASD children showed higher interest towards humans, e.g. their parent, than the TD children did, they showed less interest towards pet compared to the TD children. Our results suggested that animals are not inherently easy to decode for ASD children, in contrast with previous experiences where a pet was regarded as a more attractive partner, easier to be understood. At last, the ASD children changed more frequently their focus point than the TD children did. These differences may be explained by the reduced attention skills in ASD or the study's context. To conclude, larger exploratory studies in natural settings conducted beyond ordinary human to human interactions, are crucial for better understanding of the underlying mechanisms involved in social interactions in ASD.
\end{abstract}

Key words: autism spectrum disorders, ethology, child-pet relationship, attention, social interaction 
Some crucial aspects of living in a social group are showing interest towards others and interacting with others [61]. This is called social attention, a key component of social cognition.. The latter is mediated by neural circuits which transfer sensory information about others and process that information into value signals (i.e. the functional role of. superior temporal sulcus or STS; [1]). Several cues indicate the focus of person's attention: eye-gaze direction, directed behaviors, head position, body position, pointing gestures [7]. Attention directed towards other people, social attention, is important in human interactions as it is involved in the genesis of social bonds, inducing social codes [54]. Pashler [53] explained that social attention is constituted of selective attention (i.e. directed towards a particular phenomenon in the face of competing stimuli) and divided attention (i.e. sharing out concentration on more than one stimuli). Both types of attention are implied, for example, in children's development. Indeed, children involved in social situations are more alert and mindful, and consequently more prone to react and to memorize [19], especially language development during which infants are influenced by social cues [24]. Throughout direct social contacts and interactions, children could maintain their perceptual abilities, for example, to discriminate phonetic units [43]. This stresses that social attention is strongly linked to perception and could modify it [60]. It is worth mentioning that the importance of social influences and attention skills during development has been evidenced in a variety of species and not only in humans [42, 67]. And attention difficulties, such as in joint attention, are absent or impaired in some psychiatric disorders or neurodevelopmental disorders, e.g. autism spectrum disorders (ASD) [5, 48].

Currently, most researchers studying ASD agree on a neurodevelopmental origin of these disorders. During brain development, some mechanisms of regulation seem to be impaired $[14,21]$ leading to a cascade of developmental abnormalities. ASD's symptoms and characteristics are the consequences of such developmental abnormalities, e.g. attention deficits, pervasive disruptions of social abilities, difficulties to communicate and to establish social bonds [4] [16, 39]. For example, impairment of visual attention is correlated with both general [23] and more specific abnormalities such as those affecting social abilities (e.g. making less frequent eye contact [17]), inattention to faces [52] or fail to reliably attend to facial expressions [40]). Thus, one could propose that attention dysfunction processes observed in individuals with ASD may be correlated with a core deficit linked to their 
communication and their social interaction impairments [3]. Despite this extended interest in the area of attention in ASD, there are yet unclear areas that we aim at exploring hereunder.

Clinical observations on ASD often report a striking lack of (1) interest in people, (2) responsiveness towards people, (3) social interactions and communicative behaviours [16, 36] and yet an interest towards inanimate objects [16]. The social deficits in ASD may be associated with a lack of understanding of non-verbal signals, intentions and mental states of other individuals as well as failure to process social stimuli to generate social interactions [20, 71]. The latter being strongly correlated with social attention skills [7, 38], some authors propose that attention impairments may contribute to the profound social disabilities characterizing ASD. For example, one stressed the quality of early social exchanges [15]. Infants need to shift their attention rapidly between different stimuli when they share their attention with others. However, this ability is altered in ASD [13]. Another author focused on the nature of stimuli (i.e. animate or inanimate) Even if general impairments in ASD are related to attention orienting and shifting, they are also related to the nature of social stimuli [15]. Indeed individuals with ASD have difficulty processing and representing complex, variable, and unpredictable social stimuli (e.g. facial expressions, speech, gestures [16]). Their attention does not seem to be drawn naturally to these stimuli.

Experimental research on ASD raises some questions with regard to interest and attention in animate agents. For example, both children and adult with ASD have been presented to a change detection performance task to assess attention [49]. New et al. [49] observations on ASD alternating animate or inanimate stimuli in a natural setting, reported a significant difference between the two types of stimuli. Interestingly, individuals with ASD are able to pay real attention, especially to human beings. They showed the same social attention to animate stimuli (i.e. human and animal) as participants with TD. In this paper, New et al. [49] suggested to study attention as an additional dimension to social interaction in the observations of perception and cognition in ASD, especially in ethology related field work. This methodological requirement was previously advised (e.g. $[37,76]$ ), especially to investigate individuals with ASD in natural settings that is in their "real life" environments. For example, Hutt and Ounsted [33] showed in a free-play situation that ASD children played more solitary than TD children. More surprisingly, ASD children seek more adult contact than TD children. This interest for adult partner is consistent with other studies (e.g. [56, 70]). Even if the behaviours displayed by ASD children were more object-directed than humandirected, the adult sharing the play situation remains a non-negligible target of child's visual 
attention, especially the gazes [70]. A recent study on ASD and TD children showed similar results at child's home - only one third of the ASD children were immediately attracted to human adults rather than to a new pet. This behaviour was not observed in their TD counterparts [26, 27]. Prothmann et al. [59] observed ASD children in a lab experimental setting to test the ASD children interaction target preference (i.e. dog versus human versus object). Interestingly, ASD children interacted more frequently and longer, respectively, with the certified therapy dog than with the human than with the objects. Consistent with earlier works [62], Prothmann et al. [59] proposed that animal's behaviour could be more predictable and easier to decode than those of a human partner. However, further investigations are needed.

Taken together, these studies showed numerous differences. One could debate over the impact of the context (i.e. familiar or unfamiliar) on the behaviour of individuals with ASD. Are there fewer stakes involved when facing a computer screen (e.g. eye tracking) or being in a natural setting (e.g. home) than being in a clinical setting (e.g. for diagnosis)? Could an animal presence be a facilitator? In such context, the aim of our study was to assess the ASD and TD children interest towards human, animal and object in a natural setting (e.g. child's home). We deployed our study through an ethological approach involving observations in children's home. We focused firstly on social attention (e.g. behaviour directed towards, gazed at) in the presence of a pet, two humans (i.e. parent and observer) and objects, either familiar or unfamiliar to the participants. Indeed, ASD children have the ability to process social familiarity (i.e. attention towards familiar social features). They are more prone to respond with empathy to a familiar agent [32] and their familiarity with the observer has a significant positive effect on their behaviour and testing performance [69]. Secondly, we assessed attention skills by calculating two global indexes: "focus on a target" (visual focusing) and "shift between targets" (visual shifting).

\section{Materials and Methods}

\section{Subjects}

Data were collected at children's homes over 9 months between Summer 2008 and Spring 2009.

The target population 
General information

Participants were 90 French children, all aged between 6 and 12 years old (Table 1). Thirty one ASD children were recruited from the "Centre de Ressources sur l'Autisme de Bretagne", Bohars, France. They were matched for chronological age with 59 TD children; Mann Whitney test, $\left.\mathrm{n}_{1}=31 \mathrm{n}_{2}=59 \mathrm{U}=2695.5 \mathrm{p}=0.929\right)$. The TD children attended school regularly; none met any diagnostic criterion for ASD or other pervasive developmental disorders.

Characterization of autism spectrum disorders

Behavioural assessments have been performed using the Autism Diagnostic InterviewRevised [46]. The ADI-R, an extensive, semi-structured parental interview, was conducted by independent psychiatrists. The ADI-R scale assessed the three major domains of ASD: reciprocal social interactions, verbal and non-verbal communication, stereotyped behaviours and restricted interests. The severity of impairments in these three major domains of ASD was scored using the subset of ADI-R items included in the ADI-R algorithm: total social interaction score (15 items; threshold of 10), total verbal/nonverbal communication score (13 items, or for non verbal patients, 9 items; threshold of 8 and 7 respectively) and total stereotypies score (8 items; threshold of 3). A total score of ADI-R algorithm was also obtained ( $\mathrm{n}=31$ ASD children; table 1). The presence of verbal language skills is defined as daily, functional and comprehensible use of spontaneous phrases of at least three words and occasionally a verb. Here, all TD children and 21 ASD children expressed verbal language (i.e. 67.7\%; Table 2). The Vineland Adaptive Behaviour Scales (VABS) is a parent interview that assesses children's functional skills in four behavioural categories: communication, daily living skills, socialisation and motor skills [68]. In the current study, we only used communication, daily living skills and socialisation sub-scales ( $\mathrm{n}=20$ ASD children; Table 1). Childhood Autism Rating Scale questionnaire (CARS [64]) was employed by the psychiatrists for 20 ASD children. The CARS-scale is a behaviour rating scale intended for evaluating the level of autism with a maximum score of 60 . The higher the score, the more severe autistic behaviour the child exhibits. Here, our population was mainly composed of children with mild ASD (Table 1).

Based on direct clinical observation of the child by independent child psychiatrists, a diagnosis of ASD was made according to DSM-IV [3] as well as ICD-10 [75] criteria and was confirmed by ADI-R ratings. 


\section{[INSERT TABLE 1]}

Experience with pets

The children had different prior experience with companion animals (see Table 2 for details). This information was obtained from a short standardised parental questionnaire about companion animals and their children. This questionnaire was previously developed and used $[25,28]$. Parents were asked about their pet ownership (i.e. the current presence of a pet in the child's home), the presence of privileged relationships between their child and their own companion animals (i.e. favourite pet of the child, spending time and playing together and reciprocal behaviours). Negative child-pet relationships were also explored with the census of any prior negative experience with an unfamiliar animal (e.g. have been bitten).

\section{[INSERT TABLE 2]}

\section{Ethical note}

All children were accompanied by one of their parents during the test. It is worth mentioning that the present research was non-invasive and did not involve pharmacological interventions. Hence, in accordance to the ethics committee, parents gave only an informed written consent to allow the child's participation in the experiment and to film their child prior to their inclusion in the study.

\section{Experimental design}

\section{Animal subjects used in the study}

Four brown long-coat and non-parturient adult female guinea pigs (Cavia porcellus) were chosen for their particular characteristics. Guinea pig is a clawless, non-aggressive rodent species with attractive features enhancing interactions with a child [42]. In contrast to cat or dog, as a more neutral and less interactive species, a guinea pig can bring out the most of the child's behavioural repertoire. This eases the study of children's attitudes. Before their experimental use, the guinea pigs were kept by a family and were handled regularly. To avoid excessive stress or weariness, each guinea pig underwent a maximum of three experiments per day ( $\bar{X}=1.6$ experiments \pm 0.8 experiments).

The pet device included a standard cage $(70 \times 40 \times 20 \mathrm{~cm})$, cleaned before each experiment. To facilitate interactions, the pet's shelter and the cage top were removed. The cage floor was 
covered with sawdust. Water and food (commercial pellets and hay) were provided ad libitum.

\section{Experimental context}

An appointment of one hour was set between the observer and the family at least 2 weeks before the experiment. All experiments were performed at children's homes to avoid ASD children's anxiety of unfamiliarity. Even if the research focused on child-pet interaction, the presence of one parent was asked. Thus, during the experiment, two adults were present in the room: one parent (i.e. familiar human) and the observer (i.e. unfamiliar human). The mother was usually the parent present during the experiment, except for single father families or when the mother was temporarily absent. $\left(n_{m}=80\right.$ and $n_{f}=10$ respectively). All tests were performed by the same observer (female, blond hair).

\section{Procedure}

Before setting up the experiment, the observer instructed the child and his/her parent as follows:

- The child: during the experiment he/she could behave as he/she wanted. For example, he/she was free to interact (or not) with the unfamiliar animal. We stressed to the child and the parent that no behaviour was considered either right or wrong.

- The parent: during the experiment, he/she was asked to sit away from the cage, to stay neutral and silent (e.g. no encouragements, no smiles to the child). The parents of ASD children were asked to confirm that their children had heard/understood the instructions.

After assuring that the given instructions have been understood, the equipment was installed. Both the animal's and the child's behaviours were recorded using two video cameras, one mounted on a tripod and facing the cage (focusing on the animal's behaviour) and the second one carried by the observer (focusing on the child's behaviours). The open cage was placed on a low table (for details, see [26]). These elements constituted unfamiliar objects for the children. The other objects of the environment (e.g. television, toys) are considered as familiar objects.

When all the equipment was installed, the observer then asked the child and the parent to come into the room. As soon as they entered, the observer switched on both cameras. The observer remained neutral and silent in an unobtrusive place in the room, she moved only if absolutely necessary in order to avoid losing view of the child forefront part of the body (e.g. 
child with his/her back to the observer) and stopped the experiment after 15 minutes. Only one experience where stopped after 12 minutes because the interaction became too "intense" (mostly rough handling of the guinea pig).

\section{Data collection and analyses}

\section{Data collection}

Ethological methods of data sampling were used. Thus, the children's behaviour was analyzed later by instantaneous scan sampling. Altmann [2] explained this technique in which the observer records an individual's current activity at preselected moments in time (e.g. every minute throughout the day). Such sampling is used to study the percent of time spent in various activities. It is a discrete sample of states, i.e. of ongoing behaviours, and not events. It is true that under some conditions, some information could be lost (i.e. transition time between each state). Thus, researchers need to ensure that instantaneous scan sample intervals are short enough to reduce this loss. Consequently, ten-second intervals were chosen leading to 90 scans per session.

The recorded behavioral items were:

1. Body part of the child nearest to the guinea pig: face, hand/arm, trunk, back, leg or foot

2. Direction of the child's eyes (independently of behaviors): gaze directed towards the guinea pig, a human being (observer or parent) or an object (either unfamiliar objects camera, cage - or familiar objects in the room), self-centered (e.g. hands). Eye orientation was measured when within $5^{\circ}$ of a target.

3. Child behaviour: child displayed either behaviours directed towards human (parent or observer) or pet (tactile, vocal or visual) or non-interactive behaviours as showing interest in an object, locomotive behavior or displaying stereotypies (Table 3 for codebook).

4. Spatial distance between the child and the pet was measured in terms of child's arm length to contact ( 0 to $1 / 2,1 / 2$ to 1,1 to $1 \frac{1 / 2}{2},>1 \frac{1}{2}$ ). We also recorded as "out" when the child left the room.

\section{[INSERT TABLE 3]}

The observation of the above items and the recording of the events during the session were performed by the same rater (YB). For reliability purposes, another rater (MG) coded $10 \%$ of 
the video recordings, chosen randomly, in accordance with the codebook of the behavioural items used in this study. The degree of correlation between these two raters was established by calculating Cohen's Kappa. Reliability was excellent (Total: 0.91, Body part of the child nearest to the guinea pig: 0.93, Direction of the child's eyes: 0.85; Child behaviour: 0.93 Spatial distance: 0.94; [45]). Both raters had previous experience in coding human-animal interactions.

\section{Data analyses}

Instantaneous scan sampling yielded two types of data [2]: (1) frequency (in \% of scans) of different behavioural items recorded (i.e. general behaviour, nearest body part and eye direction) and (2) frequency of time spent at a given distance category from the pet (i.e. proximity).

As ASD children display attention difficulties [4], two indexes were developed and aimed at assessing visual attention. Visual attention data were collected by evaluating the degree of (1) visual shifting and (2) visual focusing. The degree of visual shifting was estimated by the percentage of visual target changes between two consecutive scans (i.e. number of target changes/total of 89 scans $X 100$ ). The degree of visual focusing was estimated by the percentage of unchanged visual target between two consecutive scans (i.e. number of scans without a behaviour change/total of 89 scans X 100).

\section{Statistical analyses}

As our data did not fit a normal distribution, we applied non-parametric statistical tests [65]. Significance threshold was $\mathrm{p}=0.05$. Mann-Whitney U-tests were used to compare two independent samples (e.g. the difference in factor effects between the two groups). KruskallWallis and Wilcoxon Signed Rank tests were used to compare dependent samples (e.g. the difference in behaviours among the same group). Spearman tests were used to evaluate the correlations.

\section{Results}

\section{General behavioural trends}

\section{Interest for the pet}

Results were detailed in table 4. 
Both TD children and ASD children showed more interest towards an unfamiliar pet than humans or objects (Kruskall-Wallis tests, $\mathrm{p}<0.001$ ). Moreover, behaviours towards the pet were more reported in TD children than in ASD children $(\mathrm{p}<0.001)$. The results of child's eye direction towards the pet were more significant $(\mathrm{p}<0.001)$ in TD children than their ASD counterparts.

\section{[INSERT TABLE 4]}

Three types of directed behaviours towards the pet had been recorded: tactile, vocal and visual behaviours (Table 4). The TD children displayed more often tactile behaviours towards the pet than visual and vocal behaviours $(\mathrm{p}<0.001)$. Conversely, the ASD children displayed more often visual behaviours towards the pet than tactile behaviours $(\mathrm{p}=0.001)$. Thus, TD children displayed more tactile and visual behaviours towards the pet than the ASD children did ( $p<0.001, p<0.018$ respectively). Interestingly, no difference in vocal behaviours towards the pet was observed between the two groups $(\mathrm{p}>0.999)$

Child-pet distances differed between the two groups: ASD children were more observed at greater distances from the pet ( $>1$ child's arm; $\bar{X} \pm \mathrm{SD}=73.7 \pm 13.2$ ) than were TD children and conversely, TD children were observed closer to the pet ( $<1 / 2$ child's arm; $\bar{X} \pm \mathrm{SD}=76.3 \pm 13.3$ ) than were ASD children ( $<<0.001$; Fig. 1). The body part nearest the pet differed between the two groups (Table 4). The TD children preferred arm/hand whereas no preferred body part was observed in ASD children $(\mathrm{p}<0.001)$. The ASD children had more their backs or their trunks closest to the pet than TD children (for both body parts, $\mathrm{p}<0.001$ ).

At last, ASD children displayed more behaviours towards the human beings and towards objects than did TD children ( $\mathrm{p}<0.001, \mathrm{p}=0.045$, respectively; Table 4$)$.

\section{[INSERT FIGURE 1]}

\section{Interest for familiar and unfamiliar humans}

ASD children directed more their behaviours towards the familiar human $(\bar{X} \pm \mathrm{SD}=2.4 \pm 2.2)$ than towards the unfamiliar human $(\bar{X} \pm \mathrm{SD}=0.7 \pm 0.8 ; \mathrm{Z}=1.9, \mathrm{p}=0.05$; Fig $2 \mathrm{~A})$. This difference was not observed for TD children (familiar human: $\bar{X} \pm \mathrm{SD}=0.6 \pm 1.0$; unfamiliar human: $\bar{X} \pm \mathrm{SD}=0.09 \pm 0.2 ; \mathrm{Z}=1.4, \mathrm{p}=0.159 ;$ Fig $2 \mathrm{~A})$. Moreover, ASD children directed their behaviours more towards the familiar human and the unfamiliar human than TD children did 
(all Mann-Whitney U-tests p<0.001; Fig 2A). At last, ASD children looked more at the familiar human and at the unfamiliar human than TD children did (both $\mathrm{p}=0.001$; table 4)

$$
\text { [INSERT FIGURE 2] }
$$

\section{Non-interactive behaviours}

The ASD children directed their behaviours more towards familiar objects $(\bar{X} \pm$ $\mathrm{SD}=28.3 \pm 16.5)$ than towards unfamiliar objects $(\bar{X} \pm \mathrm{SD}=4.2 \pm 4.2 ; \mathrm{Z}=378, \mathrm{p}<0.001 ;$ Fig $2 \mathrm{~B})$. A similar difference was observed for in the TD children (familiar objects: $\bar{X} \pm \mathrm{SD}=13.4 \pm 9.0$; unfamiliar objects: $\bar{X} \pm \mathrm{SD}=5.4 \pm 2.8 ; \mathrm{Z}=0, \mathrm{p}<0.001$; Fig 2B). The ASD children and TD children directed their eyes more towards familiar objects than towards the unfamiliar objects (both Wilcoxon tests $\mathrm{p}<0.05$ ). The ASD children directed their behaviour more towards and looked more towards familiar objects than did TD children (all Mann-Whitney U-tests, $\mathrm{p}<0.001$; Fig 2B, table 4). Conversely, TD children looked more towards unfamiliar objects than did ASD children $(\mathrm{p}<0.001$, table 4$)$.

Lastly, ASD children displayed more stereotypies $(\bar{X} \pm \mathrm{SD}=10.0 \pm 10.8)$ than TD children did $(\bar{X} \pm \mathrm{SD}=0.0 \pm 0.0 ; \mathrm{U}=2281, \mathrm{p}<0.001)$. No difference was reported for locomotion behavior (Mann-Whitney U-test, $\mathrm{p}>0.05$ ).

\section{Children's visual attention skills}

The index of visual shifting was higher for ASD children than for TD children $(37.7 \% \pm 19.3 \%$ versus $24.0 \% \pm 12.5 \%$; $\mathrm{U}=2284.5$, $\mathrm{p}<0.001$; Fig 3). Conversely, the index of visual focusing was higher for TD children than for ASD children (7.1\% $\pm 7.1 \%$ versus $4.5 \% \pm 4.8 \%$; $\mathrm{U}=951.5$, $\mathrm{p}<0.001$; Fig 3). More precisely, the visual index only focusing at the pet was higher for TD children than for ASD children $(11.4 \% \pm 10.9 \%$ versus $6.3 \% \pm 9.8 \%$; $U=3217.5, \mathrm{p}<0.001)$.

\section{[INSERT FIGURE 3]}

\section{Effects of different factors}

Even though general behavioural trends were consistent among each group, interindividual variations emerged and were large for some variables. Therefore, we investigated in more detail the effects of different factors on behavioural expression. Only the statistical significant effects were reported below. 


\section{Children's verbal language level}

Having - or not having - a verbal language influenced significantly ASD children's behaviour. Compared with non-verbal ASD children, verbal ASD children were observed closer to the pet (contact or $<1 / 2 \mathrm{arm}$; all Mann-Whitney U-tests, $\mathrm{p}<0.01$ ), hand/arm were their nearest body part $(\mathrm{U}=47.5, \mathrm{p}=0.016)$, they looked more towards the pet $(\mathrm{U}=88.5, \mathrm{p}=0.003)$ and they directed more behaviours towards it, especially tactile behaviours (both MannWhitney U-tests, $\mathrm{p}<0.01)$. On the contrary, non-verbal ASD children displayed more stereotypies than verbal ASD children did $(U=25, p<0.001)$. The former remained farther from the pet $\left(<1 \frac{1}{2} 2 \mathrm{arm}\right.$ or out the room; all Mann-Whitney U-test, $\left.\mathrm{p}<0.05\right)$ and legs were their body part nearest the pet $(\mathrm{U}=56.5, \mathrm{p}=0.015)$.

\section{Experience with animals}

The pet owner TD children talked more to the pet than non-pet owner TD children $(5.1 \pm 5.4$ and 1.2 \pm 1.2 , respectively; $U=566, p=0.018$ ). Very interestingly, while the mere presence of a pet in their home did not appear to significantly influence ASD children's behaviour towards our unfamiliar pet $(51.4 \pm 20.0$ for the non pet owners and $46.2 \pm 19.9$ for the pet owners, $\mathrm{U}=146.5, \mathrm{p}=0.93$ ), the quality of relationships established with their own pet appeared to be a determinant in the child-pet interaction. The ASD children with privileged relationships (ASD children $_{P R}$ ) were more attracted to the pet than the other ASD children pet owners (behaviours turned to the pet: $68.2 \pm 16.3$ and $27.8 \pm 18.4$ respectively; $U=107, p=0.43$ ). Precisely, the ASD children $_{\mathrm{PR}}$ used more tactile contact with the pet than the other ASD children pet owners did (40.1 \pm 17.4 and 12.4 \pm 13.9 respectively; $U=106, p=0.029)$. The ASD children ${ }_{P R}$ looked more at the non familiar objects than the other ASD children pet owners did $(5.2 \pm 2.2$ and $1.3 \pm 1.4$ respectively; $U=95, p=0.005$ ). At last, $T D$ children seemed to develop more often a privileged relationship with their pets $(54.2 \%)$ than did ASD children $\left(35.5 \% ; \mathrm{X}^{2}=2.86, \mathrm{p}=0.09\right)$.

The children who previously had prior negative experience with animals seemed to behave more cautiously. However, there was no difference between the $\%$ of those with a prior negative animal experience among ASD and TD children (29\% and 15.2\% respectively, $\mathrm{X}^{2}=2.41, \mathrm{p}=0.12$ ). Of these children who previously had negative experiences with an animal, fewer TD children were observed near the pet than their counterparts $(<1 / 2 \mathrm{arm}$; $U=96$, $\mathrm{p}=0.007$ ); larger number of ASD children expressed behaviours towards their parent than their counterparts $(\mathrm{U}=46, \mathrm{p}=0.04)$. 


\section{Discussion}

This study revealed that the ASD children displayed interest towards animate stimuli (i.e. pet and humans) rather than inanimate ones (i.e. objects) in a natural setting (i.e. at home). They changed more frequently their attention focus point than TD children did. Moreover, the ASD children were less attracted to an unfamiliar pet even if their behaviours appeared influenced by their verbal language and their prior experience with animals.

Our study revealed that the ASD children were interested towards an unfamiliar pet, but that this attraction was less important than that of the TD children. They stayed at a greater distance from the pet and thus, used more distant behaviours, i.e. visual behaviours towards the pet. This spatial area that individuals maintain around themselves, named personal space, could imply discomfort or even anxiety when others intrude into it. It has been shown that ASD children feel more comfortable socially at a greater personal space than TD children [22]. Our spatial behaviour results were consistent with this recent observation, but here, involving a pet. Moreover, anecdotal reports have suggested that ASD children could easily interact with pets $[12,66]$. Some authors proposed that animals may be simpler to decode than human beings [47, 62]. However, showing interested towards an animal seems to be influenced by several factors. In our study, it was influenced by the quality of the child's relationship with the pet and the child's prior experience with animals. Firstly, the ASD children who made privileged relationships with their own pet were more attracted to our unfamiliar guinea pig. If experiencing such relationships has a short-term influence on children's behaviours, a long-term impact has also been highlighted. Indeed, ASD children who experience the arrival of a pet in their home show significant changes in their social skills linked to empathy [28]. Moreover, developing a privileged relationship with a pet implies a rich panel of interactions, in both ASD and TD children [25]. In addition, specific interactions with specific animals could enhance learning about animals in general $[6,55]$. Secondly, in our study, children who had a prior negative experience with an animal behaved more cautiously thus interacted more with their parent, a potential source of reassurance. ASD children seem to have expectations about the pet's possible behaviour based on past experience with other animals [30]. Altogether, our results suggest that animals are not inherently easy to decode as previously stated. We propose that experiences with animals 
could change a pet into a more attractive partner, easier to be understood by ASD children. The explanation may be the interaction between different factors, including well-known aspects as well as yet unexplored aspects. Further studies are thus needed to support our hypothesis.

Some social behaviours (e.g. social gaze) are related to factors such as chronological age, social context or level of functioning in ASD [74]. For example, cognitive levels influence daily behaviours such as watching television or playing with a parent since low-functioning children have been reported to initiate fewer interactions than high-functioning children [29, 72]. These studies showed that cognitive skills influence the social initiations displayed by ASD children. The strong association between the verbal language and the nature of child-pet interactions has been previously reported by parents [25]. Consistent with these previous results, we observed that verbal children (i.e. high-functioning) looked at and touched the pet more than non-verbal children did (i.e. low-functioning). This suggests that the level of functioning must be taken into account in research including animals and in interventions assisted by animals to clarify the initial goals and potential improvements.

Our results showed that ASD children changed more frequently their attention focus point than TD children in a natural setting. This revealed a difference in the structuring of attention but not necessarily in the quality of attention. These findings were consistent with neurophysiologic approach (e.g. [13]) or behavioural approach (e.g. [63]) where reduced attention skills were highlighted. Other non exclusive explanations could be given. We suppose that such results could be different if the parent participated and helped the child in their interactions with our guinea pig. Indeed, parental involvement in child support plays an important role in immediate and long term effects [11]. Furthermore, interest towards animate agents was observed here, as the ASD children directed more gazes at, and more behaviours towards, the pet and the human beings, especially their parent. These results confirm previous studies using a lab setting with static stimuli [49] or using direct observations [59], and contrast the widely supposed lack of interest in people $[16,36]$. Turning towards their parent rather than towards the observer could be explained by processing deficits related to face configuration of the picture $[31,41]$ and dysfunction of the fusiform face area [58] when in the presence of unfamiliar faces. Fusiform face area activation is normal when ASD children and TD children looked at familiar faces [57]. These results have been confirmed by clinical data showing that ASD children are able to recognize familiar adults when in the context of forced choice familiar face recognition task. Interestingly, they use the same face feature 
information as do the TD children [73]. As recent studies have shown that social impairments in ASD children seem to be characterized by poor social understanding and skills rather than a lack of interest in humans $[8,15,51]$, we suppose that ASD children would find it easier to turn towards the parent (i.e. familiar partner) and, more widely, towards the familiarity rather than the unfamiliarity. Our study suggests that ASD children seek comfort or help when turning towards humans, as previously shown in other strange situations $[9,44]$.

Recent studies have shown the existence of variations in ASD severity according to the study context. This could give to variation pairs such as observed behaviours and rater's identity [35], sensory and environmental context [10], imitation and experimental context [34] or empathy and emotional context [32]. We could hypothesize that familiar context (i.e. home environment and parent) may not be as stressful as clinical settings. ASD children may express different attention skills subjected to the nature of their setting and the context. For instance, ASD children may display more visual attention when facing natural and familiar context. Further studies are needed to explore the difference between familiar and unfamiliar partners and objects as well as context-dependent skills, including social attention and brain processing.

Our study was limited by its cross-sectional design. Our results cannot be extrapolated to a general population of ASD children. Here, the study design bias was reduced by a good sample size of ASD children. We propose to repeat this experiment with another sample of ASD children and guinea pigs to validate our present results, especially to explore more precisely the impact of children's prior experience with animals.

In conclusion, this study revealed, for the first time in a natural standardized setting that ASD children showed a similar interest towards animate stimuli as TD children did. Using a natural setting constitutes a methodological alternative to lab static setting and it should be applied to further research. Studying social interactions, beyond ordinary human-human interactions, is crucial to fully understand the social mechanisms and processes involved in ASD. Thus, our experiment using ethology could be used further as an interesting tool for understanding ASD. 


\section{Conflict of interest}

All the authors have no conflict of interest, no financial and personal relationships with other people or organizations including employment, consultancies, stock ownership, honoraria, paid expert testimony, and travel grants all during the conduction and termination of the work submitted. 


\section{REFERENCES}

1. Allison T, Puce A, McCarthy G (2000) Social perception from visual cues: Role of the STS region. Trends Cogn Sci 4:267-278

2. Altmann J (1974) Observational study of behaviour: Sampling methods. Behaviour 49:227-267

3. American Psychiatric Association (1994) Diagnostic and Statistical Manual of Mental Disorders. Washington

4. Ames C, Fletcher-Watson S (2010) A review of methods in the study of attention in autism. Dev Rev 30:52-73

5. Baron-Cohen S, Leslie AM, Frith U (1985) Does the autistic-child have a theory of mind. Cognition 21:37-46

6. Beck AM, Melson GF, da Costa PL, Liu T (2001) The educational benefits of a tenweek home-based wild bird feeding program for children. Anthrozoos 14:19-28

7. Birmingham E, Kingstone A (2009) Human social attention: A new look at past, present, and future investigations. Ann. N. Y. Acad. Sci. 1156:118-140

8. Boucher J (2012) Research review: structural language in autistic spectrum disorder characteristics and causes. J Child Psychol Psyc 53:219-233

9. Bretherton I, Ainsworth MDS (1974) One-year-olds in the Strange Situation. In: Lewis M, Rosenblum L (eds) The origins of fear. Wiley, New York, pp. 131-164.

10. Brown NB, Dunn W (2010) Relationship between context and sensory processing in children with autism. Am J Occup Ther 3:474-483

11. Burrell TS, Borrego J (2011) Parents' involvement in ASD Treatment: what is their role? Cogn Behav Pract 19:423-432

12. Condoret A (1983) Speech and companion animals, experience with normal and disturbed nursery school children. In: Katcher AH, Beck AM (eds) New Perspectives in our Lives with Companion Animals. University of Pennsylvania Press, Pennsylvania, p 467-471

13. Courchesne E, Chisum H, Townsend J (1994) Neural activity-dependent brain changes in development - implications for psychopathology. Dev Psychopathol 6:697722

14. Courchesne E, Mouton PR, Calhoun ME, Semendeferi K, Ahrens-Barbeau C, Hallet MJ, Carter Barnes C, Pierce K (2011) Neuron number and size in prefrontal cortex of children with autism. JAMA 306:2001-2010

15. Dawson G (1989) Autism: Nature, diagnosis, and treatment. The Guilford Press, NewYork.

16. Dawson G, Melzoff AN, Osterling J, Rinaldi J, Brown E (1998) Children with autism fail to orient to naturally occuring social stimuli. J Autism and Dev Disord 28:479-485

17. Dawson G, Osterling J, Meltzoff AN, Kuhl P (2000) Case study of the development of an infant with autism from birth to two years of age. J Appl Dev Psychol 21:299-313

18. Dixon LM, Duncan IJH, Mason G (2008) What's in a peek? Using fixed action pattern morphology to identify the motivational basis of abnormal feather-pecking behaviour. Anim Behav 76:1035-1042

19. Doupe AJ, Kuhl PK (1999) Birdsong and human speech: Common themes and mechanisms. Annu Rev Neurosci 22:567-631

20. Frith CD, Frith U (1999) Interacting minds: A biological basis. Science 286:16921695

21. Frith U, Hill E (2004) Autism: Mind and Brain. Oxford University Press, USA 
22. Gessaroli E, Santelli E, di Pellegrino G, Frassinetti F (2013) Personal space regulation in childhood autism spectrum disorders. PloS One 8:e74959

23. Goldstein G, Johnson CR, Minshew NJ (2001) Attentional processes in autism. J Autism Dev Disord 31:433-440

24. Goldstein MH, King AP, West MJ (2003) Social interaction shapes babbling: Testing parallels between birdsong and speech. PNAS 100:8030-8035

25. Grandgeorge $\mathrm{M}$ (2010) Could the bond to an animal allow social and cognitive recovery in children with autism? In: UMR CNRS 6552 - Laboratoire d'Ethologie Animale et Humaine. University Rennes 2, Rennes, 357 pages

26. Grandgeorge M, Deleau M, Lemonnier E, Hausberger M (2011) The Strange Animal Situation Test. Anthrozoos 24:393-408

27. Grandgeorge M, Hausberger M, Tordjman S, Lemonnier E, Deleau M (2012) Children with autism encounter an unfamiliar pet: application of the Strange Animal Situation test. Interaction Studies 13:165-188

28. Grandgeorge M, Tordjman S, Lazartigues A, Lemonnier E, Deleau M, Hausberger M (2012) Does pet arrival trigger prosocial behaviors in individuals with autism? Plos One 7:e41739

29. Hauck M, Fein D, Waterhouse L, Feinstein C (1995) Social initiations by autistic children to adults \& other children. J Autism Dev Disord 25:579-597

30. Hinde R (1979) Towards Understanding Relationships. Academic Press, London

31. Hobson RP, Ouston J, Lee A (1988) What's in a face : the case of autism. Brit J Psychol 79:441-453

32. Hudry K, Slaughter V (2009) Agent familiarity and emotional context influence the everyday empathic responding of young children with autism. Res Autism Spect Dis 3:74-85

33. Hutt C, Ounsted C (1970) Gaze aversion and its significance in childhood autism. In: Hutt SJ, Hutt C (eds) Behavior studies in psychiatry. Pergamon press, Oxford, p 103120

34. Ingersoll B (2008) The effect of context on imitation skills in children with autism. Res Autism Spect Dis 2:332-340

35. Kanne SM, Randolph JK, Farmer JE (2008) Diagnostic and assessment findings: a bridge to academic planning for children with autism spectrum disorders. Neuropsychol Rev 18:367-384

36. Kanner L (1943) Autistic disturbances of affective contact. Nervous Child 2:217-250

37. Kingstone A (2009) Taking a real look at social attention. Curr Opin Neurobiol 19:5256

38. Klein JT, Shepherd SV, Platt ML (2009) Social Attention and the Brain. Curr Biol 19: R958-R962

39. Klin A, Jones W, Schultz R, Volkmar F, Cohen D (2002) Defining and quantifying the social phenotype in autism. Am J Psychiat 159:895-908

40. Klin A, Jones W, Schultz R, Volkmar F, Cohen D (2002) Visual fixation patterns during viewing of naturalistic social situations as predictors of social competence in individuals with autism. Arch Gen Psychiat 59:809-816

41. Klin A, Sparrow SS, de Bildt A, Cicchetti DV, Cohen DJ, Volkmar FR (1999) A normed study of pace recognition in autism and related disorders. J Autism Dev Disord 29:499-508

42. Kuhl PK (2003) Human speech and birdsong: Communication and the social brain. PNAS 100:9645-9646 
43. Kuhl PK, Tsao FM, Liu HM (2003) Foreign-language experience in infancy: Effects of short-term exposure and social interaction on phonetic learning. PNAS 100:90969101

44. Lamb ME (1975) Twelve-month-olds and their parents: Interaction in a laboratory playroom. Dev Psychol 12:237-244

45. Landis JR, Koch G (1977) The measurement of observer agreement for categorical data. Biometrics 33:159-174

46. Lord C, Rutter M, Le Couteur A (1994) Autism Diagnostic Interview-Revised: a revised version of a diagnostic interview for caregivers of individuals with possible pervasive developmental disorders. J Autism Dev Disord 24:659-685

47. Martin F, Farnum J (2002) Animal-assisted therapy for children with pervasive developmental disorders. Western J Nurs Res 24:657-670

48. Mundy P (1995) Joint attention and social-emotional approach behavior in children with autism. Dev Psychopathol 7:63-82

49. New JJ, Schultz RT, Wolf J, Niehaus JL, Klin A, German TC, Scholl BJ (2010) The scope of social attention deficits in autism: Prioritized orienting to people and animals in static natural scenes. Neuropsychologia 48:51-59

50. Nielsen JA, Delude LA (1989) Behavior of young children in the presence of different kinds of animals. Anthrozoos 3:119-129

51. Njardvik U, Matson JL, Cherry KE (1999) A comparison of social skills in adults with autistic disorder, pervasive developmental disorder not otherwise specified, and mental retardation. J Autism Dev Disord 29:287-295

52. Osterling J, Dawson G (1994) Early recognition of children with autism - a study of 1st birthday home videotapes. J Autism Dev Disord 24:247-257

53. Pashler HE (1999) The Psychology of Attention. MIT Press

54. Paterson GR (1982) Coercive family process. Castalia; Eugene, OR

55. Paul ES, Serpell JA (1993) Childhood pet keeping and humane attitudes in young adulthood. Anim Welfare 2:321-337

56. Pedersen J, Schelde T (1997) Behavioral aspects of infantile autism: An ethological description. Eur Child Adoles Psy 6:96-106

57. Pierce K, Haist F, Sedaghat F, Courchesne E (2004) The brain response to personally familiar faces in autism: findings of fusiform activity and beyond. Brain 127:27032716

58. Pierce K, Muller RA, Ambrose J, Allen G, Courchesne E (2001) Face processing occurs outside the fusiform 'face area' in autism: evidence from functional MRI. Brain 124:2059-2073

59. Prothmann A, Ettrich C, Prothmann S (2009) Preference for, and responsiveness to, people, dogs ans objects in children with autism. Anthrozoos 22:161-171

60. Puel JL, Bonfils P, Pujol R (1988) Selective attention modifies the micromechanical properties of the cochlea. Brain Res 447:380-383

61. Range F, Horn L, Bugnyar T, Gajdon GK, Huber L (2009) Social attention in keas, dogs, and human children. Anim Cogn 12:181-192

62. Redefer LA, Goodman JF (1989) Pet-facilitated therapy with autistic children. J Autism Dev Disord 19:461-467

63. Ruble LA (2001) Analysis of social interactions as goal-directed behaviors in children with autism. J Autism Dev Disord 31:471-482

64. Schopler E, Reichler RJ, Devellis RF, Daly K (1980) Toward objective classification of childhood autism : Childhood Autism Rating-Scale (CARS). J Autism Dev Disord 10:91-103 
65. Siegel S, Castellan NJ (1988) Nonparametric statistics for the behavioral sciences. McGraw-Hill, New York

66. Silva K, Correia R, Lima M, Magalhaes A, de Sousa L (2011) Can dogs prime autistic children for therapy? Evidence from a single case study. J Altern Complem Med 17:655-659

67. Snowdon C, Hausberger M (1997) Social influences on vocal development. Cambridge University Press

68. Sparrow S, Balla D, Cicchetti D (1984) Vineland adaptive behavior scales. American Guidance Service, Circle Pines

69. Szarko J (2000) Familiar versus unfamiliar examiners: The effects on testing performance and behaviors of children with autism and related developmental disabilities. Dissert Abst Intern 61

70. Tardif C, Plumet MH, Beaudichon J, Waller D, Bouvard M, Leboyer M (1995) Microanalysis of social interactions between autistic children and normal adults in semistructured play situations. Int J Behav Dev 18:727-747

71. Volkmar FR, Pauls D (2003) Autism. Lancet 362:1133-1141

72. Willemsen-Swinkels SHN, Buitelaar JK, Weijnen FG, van Engeland H (1998) Timing of social gaze behavior in children with a pervasive developmental disorder. J Autism Dev Disord 28:199-210

73. Wilson R, Pascalis O, Blades M (2007) Familiar face recognition in children with autism: The differential use of inner and outer face parts. J Autism Dev Disord 37:314-320

74. Wing L, Gould J (1979) Severe impairements of social interaction and associated abnormalities in children: Epidemiology and classication. J Disord 9

75. World Health Organization (1994) The composite international diagnostic interview, Version 1.1. Geneva: Researcher's manual.

76. Zabel RH, Zabel MK (1982) Ethological approaches with autistic and other abnormal populations. J Autism Dev Disord 12:71-83 
Fig. 1: Mean distance - evaluated in child's arm length in relation to time (in percent) between pet and child (black bars: TD children; white bars: ASD children). Level of significance: $* * * p<0.001$ (Mann Whitney U-tests). Out: out of the room.

Fig. 2: Direction of behaviour (frequency in number of scans) towards (A) familiar/unfamiliar human beings and (B) familiar/unfamiliar objects. TD children (black bars), ASD children (white bars). Level of significance: $* p<0.05$, $* * * p<0.001$, NS: non-significant (Mann Whitney U-tests and Wilcoxon tests).

Fig 3: Indexes of (A) visual shifting and (B) visual focusing of TD children (black bars) and ASD children (white bars). Level of significance: $* * * p<0.001$ (Mann Whitney U-tests). 


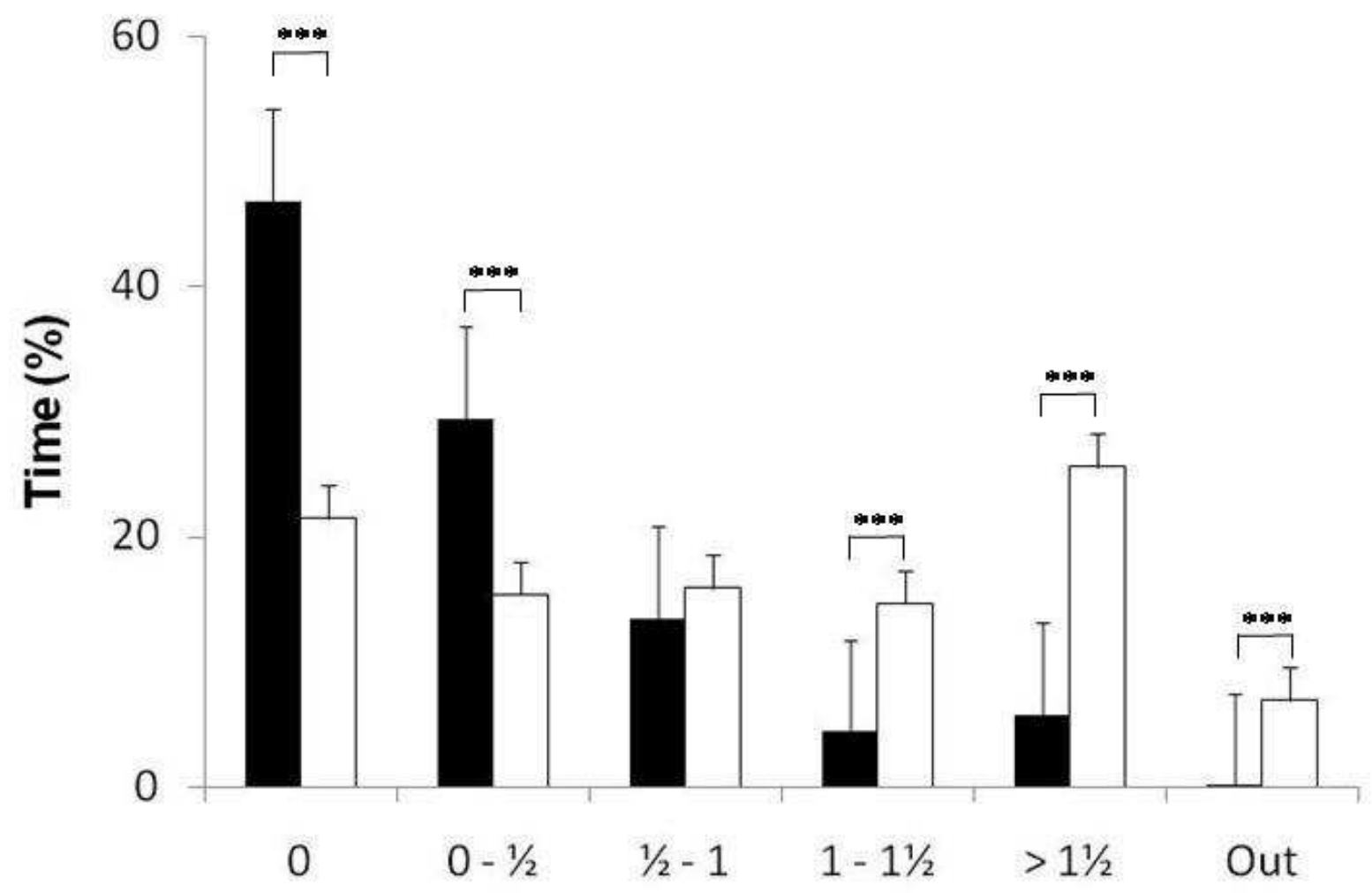



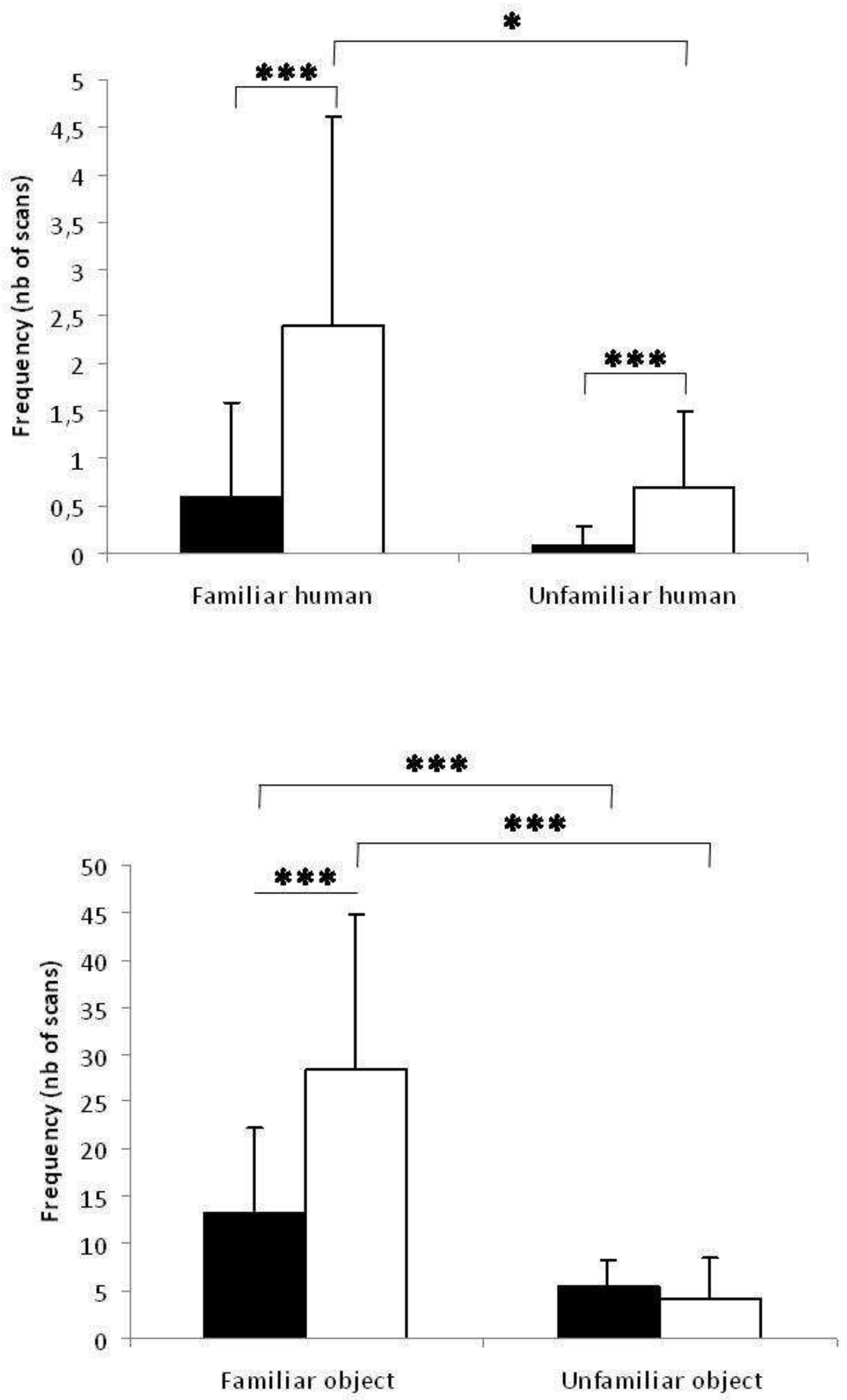


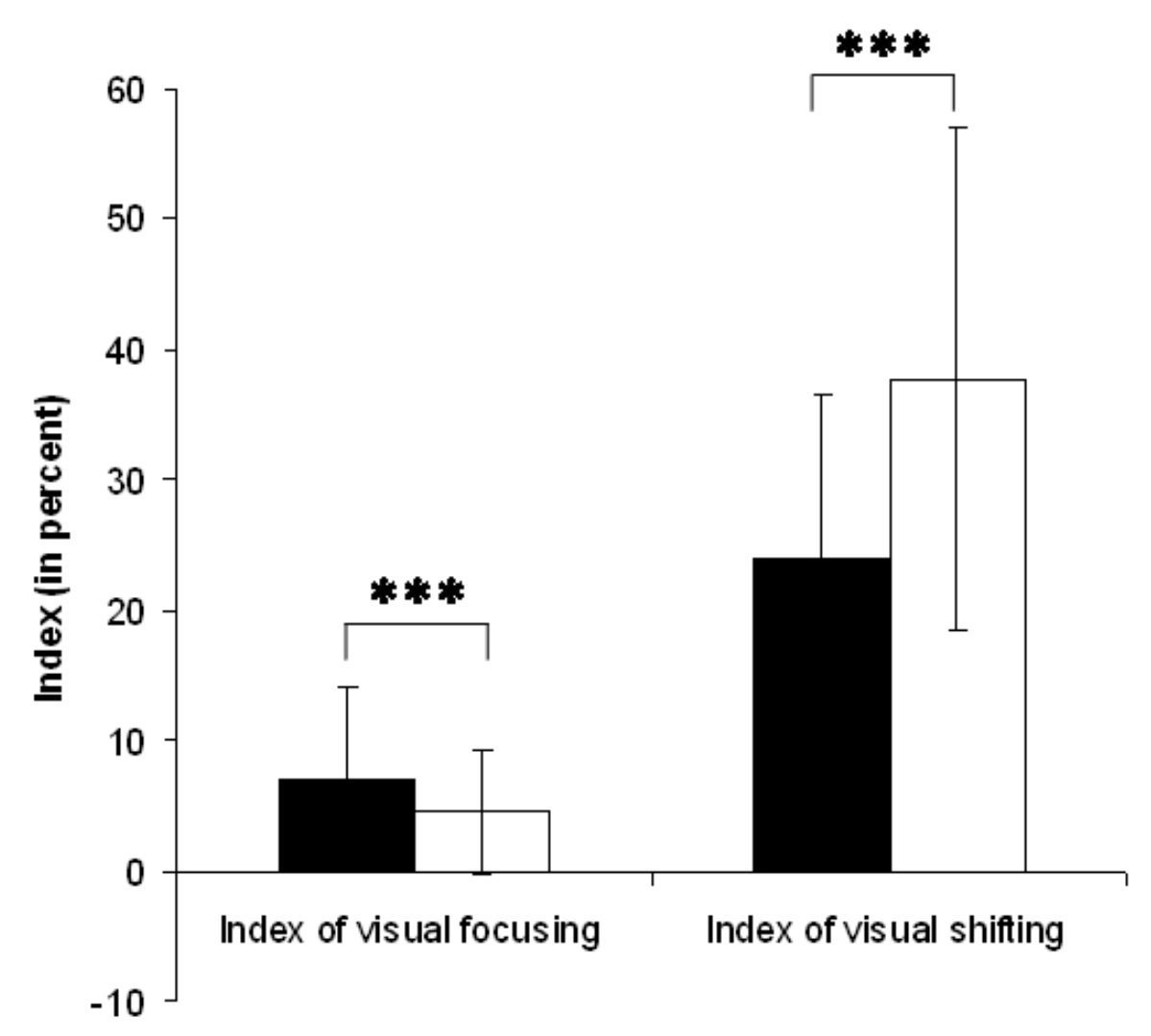




\begin{tabular}{lccc} 
& & Mean \pm SD & Min - Max \\
\cline { 3 - 4 } ADI-R $(\mathbf{n = 3 1 )}$ & Social interaction & $20.7 \pm 2.6$ & $8-29$ \\
& Communication & $15.3 \pm 2.7$ & $5-31$ \\
& Stereotypies & $5.4 \pm 1.2$ & $0-10$ \\
& Total & $41.3 \pm 4.6$ & $16-56$ \\
\hline \multirow{2}{*}{ VABS $(\mathbf{n = 2 0})$ in months } & Communication & $31.2 \pm 11.0$ & $11-83$ \\
& Daily living skills & $35.9 \pm 8.2$ & $17-81$ \\
CARS $(\mathbf{n = 2 0})$ & Socialisation & $29.2 \pm 8.6$ & $11-76$ \\
\hline
\end{tabular}

Table 1: General characteristics of the ASD children's sample according to the ADI-R, VABS and CARS. 
Children with ASD Children with typical development

\begin{tabular}{lcc}
\cline { 2 - 3 } $\mathrm{N}$ & $31\left(1+/ 30 \jmath^{\lambda}\right)$ & $59\left(32 \propto / 27 \delta^{\lambda}\right)$ \\
\hline Mean age in years $(\bar{X} \pm \mathrm{SD})$ & $9.5 \pm 1.8$ & $9.4 \pm 2.1$ \\
\hline $\begin{array}{l}\text { Presence of verbal language } \\
\text { (item 19 of ADI-R) }\end{array}$ & $21(67.7 \%)$ & $59(100 \%)$ \\
\hline Pet ownership & $22(71.0 \%)$ & $35(59.3 \%)$ \\
$\quad$ Guinea pig ownership & $1(3.2 \%)$ & $4(6.8 \%)$ \\
\hline Privileged relationships with own pet & $11(35.5 \%)$ & $32(54.2 \%)$ \\
\hline Prior negative experience with animals & $9(29.0 \%)$ & $9(15.2 \%)$
\end{tabular}

Table 2: Characteristics of the children's sample $(n=90)$. 


\begin{tabular}{|c|c|}
\hline Directed behaviour & Description \\
\hline \multicolumn{2}{|l|}{ Towards pet } \\
\hline Tactile behaviour & $\begin{array}{l}\text { The child established physical contact with the pet that is the act } \\
\text { of putting two things (a part of the child's body and a part of the } \\
\text { pet's body) together with no space between them. Here are } \\
\text { recorded all types of tactile behaviours, such as caress, stroke, } \\
\text { kiss }\end{array}$ \\
\hline Vocal behaviour & $\begin{array}{l}\text { The child uttered vocalizations or talked to the pet using "you" } \\
\text { to refer to the pet ("you're so cute") or, during talking, child } \\
\text { directed her/his gaze towards the pet }\end{array}$ \\
\hline Visual behaviour & $\begin{array}{l}\text { The child directed her/his gaze towards the pet. Looking } \\
\text { frequently accompanied vocalizations or smiling, but since we } \\
\text { wished to maximize independence of measures, "visual } \\
\text { behaviour" was only recorded when it occurred independently of } \\
\text { other social behaviors [44] }\end{array}$ \\
\hline \multicolumn{2}{|c|}{ Towards human (parent and observer were separated) } \\
\hline & $\begin{array}{l}\text { The child's behaviour was directed towards a human partner. } \\
\text { The behaviours have different natures (i.e. tactile, visual or } \\
\text { vocal) that were gathered altogether here. }\end{array}$ \\
\hline \multicolumn{2}{|l|}{ Non-interactive behaviour } \\
\hline Object interest & $\begin{array}{l}\text { The child carried an object, with or without manipulating or } \\
\text { observing it. Familiar (e.g. toy) and unfamiliar objects (e.g. } \\
\text { camera) were considered separately. }\end{array}$ \\
\hline Locomotion behaviour & $\begin{array}{l}\text { The child walked or ran about in the room. All locomotion } \\
\text { behaviours were recorded, regardless of their speed and } \\
\text { duration. Locomotion behaviour was regarded as finished when } \\
\text { the child did not walk (or run) during at least one second. }\end{array}$ \\
\hline Stereotypies & $\begin{array}{l}\text { The child displayed repeated, relatively invariable sequences of } \\
\text { movements or sounds that have no obvious purpose [18]. Verbal } \\
\text { and motor stereotypies were recorded together here. }\end{array}$ \\
\hline
\end{tabular}

Table 3: Behavioural Codebook with definition of behavioural items 


\begin{tabular}{|c|c|c|c|c|}
\hline & $\begin{array}{c}\text { ASD } \\
\text { children }\end{array}$ & TD children & Mann Whitney U-test & $\mathrm{p}$ \\
\hline \multicolumn{5}{|c|}{ Target of the behaviours } \\
\hline Pet & $47.9 \pm 19.5$ & $83.8 \pm 9.8$ & 2926 & $<0.001$ \\
\hline Humans & $3.1 \pm 2.5$ & $0.6 \pm 1.0$ & 2756.5 & $<0.001$ \\
\hline Objects & $28.3 \pm 16.5$ & $13.4 \pm 8.9$ & 1749 & 0.045 \\
\hline Kruskall-Wallis test & 28.5 & 140.2 & & \\
\hline $\mathrm{p}$ & $<0.001$ & $<0.001$ & & \\
\hline \multicolumn{5}{|c|}{ Direction of the child's eyes } \\
\hline Pet & $48.8 \pm 17.2$ & $79.7 \pm 9.6$ & 3177.5 & $<0.001$ \\
\hline Parent & $5.0 \pm 2.5$ & $1.0 \pm 0.8$ & 2248 & 0.001 \\
\hline Observer & $3.9 \pm 2.7$ & $0.7 \pm 0.7$ & 2228 & 0.001 \\
\hline Unfamiliar objects & $3.2 \pm 2.1$ & $6.9 \pm 2.8$ & 2439 & $<0.001$ \\
\hline Familiar objects & $25.7 \pm 11.9$ & $10.2 \pm 8.8$ & 2459.5 & $<0.001$ \\
\hline Self-centered & $0.6 \pm 0.5$ & $0.7 \pm 0.9$ & 701 & 0.892 \\
\hline Kruskall-Wallis test & 84.2 & 240.3 & & \\
\hline $\mathrm{p}$ & $<0.001$ & $<0.001$ & & \\
\hline \multicolumn{5}{|c|}{ Directed behaviour towards the pet } \\
\hline Tactile behaviour & $21.5 \pm 15.3$ & $46.8 \pm 14.6$ & 3133.5 & $<0.001$ \\
\hline Vocal behaviour & $4.7 \pm 4.9$ & $3.5 \pm 4.3$ & 663.5 & 0.862 \\
\hline Visual behaviour & $25.1 \pm 12.9$ & $35.4 \pm 10.5$ & 2064.5 & 0.018 \\
\hline Kruskall-Wallis test & 14.4 & 89.9 & & \\
\hline $\mathrm{p}$ & 0.001 & $<0.001$ & & \\
\hline \multicolumn{5}{|c|}{ Body part nearest the pet } \\
\hline Face & $10.6 \pm 9.6$ & $12.1 \pm 8.9$ & 848 & 0.593 \\
\hline Hand/arm & $39.1 \pm 18.5$ & $76.8 \pm 1.3$ & 3215 & $<0.001$ \\
\hline Trunk & $19.5 \pm 11.5$ & $5.5 \pm 4.8$ & 2714 & $<0.001$ \\
\hline Back & $8.9 \pm 7.7$ & $1.6 \pm 2.5$ & 2477.5 & $<0.001$ \\
\hline Leg & $6.6 \pm 6.6$ & $2.1 \pm 4.3$ & 1529 & 0.188 \\
\hline Foot & $8.4 \pm 7.8$ & $1.9 \pm 1.9$ & 1466.5 & 0.244 \\
\hline Kruskall-Wallis test & 38.1 & 203.0 & & \\
\hline $\mathrm{p}$ & $<0.001$ & $<0.001$ & & \\
\hline
\end{tabular}

Table 4: Behaviours displayed by children with ASD (ASD children) and children with typical development (TD children) in frequency (in \% of scans). Level of significance: $\mathrm{p}<0.05$ (Mann-Whitney U-test and Kruskall Wallis test) 